\title{
Glutathione S-transferase genotype increases risk of progression from bronchial hyperresponsiveness to asthma in adults
}

\author{
M Imboden, ${ }^{1,2}$ T Rochat, ${ }^{3}$ M Brutsche, ${ }^{4}$ C Schindler, ${ }^{5}$ S H Downs, ${ }^{5}$ M W Gerbase, ${ }^{3}$ \\ W Berger, ${ }^{2}$ N M Probst-Hensch, ${ }^{1}$ the SAPALDIA Team
}

\begin{abstract}
- Additional data are published online only at http://thorax.bmj. com/content/vol63/issue4

${ }^{1}$ Institutes of Social and Preventive Medicine and Surgical Pathology, Cancer Registry/Molecular Epidemiology, University of Zurich, Zurich, Switzerland; ${ }^{2}$ Institute of Medical Genetics, University of Zurich, Zurich, Switzerland; ${ }^{3}$ Division of Pulmonary Medicine, University Hospitals of Geneva, Geneva, Switzerland; ${ }^{4}$ Pneumology, University Hospital of Basel, Basel, Switzerland; ${ }^{5}$ Institute of Social and Preventive Medicine, University of Basel, Basel, Switzerland
\end{abstract}

Correspondence to:

Dr N M Probst-Hensch, Institute of Social and Preventive

Medicine, Molecular

Epidemiology/Cancer Registry, University of Zürich,

Vogelsangstrasse 10, CH-8091

Zürich, Switzerland; nicole.

probst@usz.ch

Received 13 June 2007

Accepted 18 October 2007

Published Online First

23 November 2007

\section{ABSTRACT}

Background: Bronchial hyperresponsiveness (BHR) and variation in glutathione S-transferase (GST) genes have been associated with asthma risk. The relationship of these two risk factors with adult onset asthma in the general population was investigated.

Methods: GSTP1 Ile105Val single nucleotide polymorphism and GSTM1 and GSTT1 gene deletion polymorphisms were genotyped in the populationrepresentative SAPALDIA cohort. BHR was assessed at baseline by methacholine challenge and defined as a fall of $\geqslant 20 \%$ in forced expiratory volume in $1 \mathrm{~s}$. Independent effects of GST polymorphisms and BHR on new onset of asthma after 11 years of follow-up were estimated by multiple logistic regression analysis, adjusting for relevant baseline measures. Effect modification was assessed by including interaction terms in the model.

Results: Among 4426 asthma-free participants at baseline, 14\% had BHR. At follow-up, 3.3\% reported new onset of physician-diagnosed asthma. BHR $(p<0.001)$ and GSTP1 lle105Val genotype $(p=0.005)$ were independently associated with incident asthma, but no association was seen for GSTT1 and GSTM1 gene deletion polymorphisms. Among subjects free of respiratory symptoms at baseline, the effect of BHR on the risk of physician-diagnosed asthma at follow-up was restricted to GSTP1 105 lle/lle carriers IOR 4.57, 95\% Cl 2.43 to 8.57 vs $1.40,95 \% \mathrm{Cl} 0.58$ to 3.39 ; p for interaction $=0.023$ ).

Conclusions: If confirmed by independent studies, our results suggest that GSTP1 Ile105Val genotype strongly determines the progression of BHR to physician-diagnosed asthma in the general population.

Bronchial hyperresponsiveness (BHR) has been recognised as a key feature of asthma, ${ }^{1}$ a complex respiratory disorder characterised by chronic airway inflammation, increased mucus formation, airway wall thickening and airway smooth muscle dysfunction. BHR often precedes the development of asthma, ${ }^{2-4}$ but not all subjects exhibiting BHR will develop complete expression of asthma. ${ }^{5}$ Genetic and environmental co-factors may promote or, in contrast, prevent the development of clinically relevant asthma phenotypes among subjects with BHR. Experiments in mice have shown that both airway inflammation and remodelling appear to contribute to the development, progression and persistence of BHR. ${ }^{6}$ Thus, genes expressed in bronchial tissue and involved in the modulation of inflammation and associated oxidative stress represent valid candidate genes likely to play a role as modifiers of asthma development in subjects with BHR.

Glutathione S-transferases (GSTs) are one group of candidate genes. GSTs are phase II detoxification enzymes involved in the clearing of tobacco smokederived and other toxicants. ${ }^{7}$ In addition, they have antioxidative capacities and can affect the systemic and local oxidative stress levels. ${ }^{8}$ GSTP1 is the GST gene most abundantly expressed in the lungs. ${ }^{9}$ Other highly prevalent GST variants are the homozygous gene deletions of GSTM1 and GSTT1 which are associated with lung function in the general population $^{10-12}$ and with respiratory disease..$^{13} 14$

We have previously reported that baseline BHR_including silent BHR (ie, BHR without concurrent report of respiratory symptoms)increases the likelihood of an incident asthma diagnosis within 11 years of follow-up in the population-based adult Swiss Study on Air Pollution And Lung and heart Disease In Adults (SAPALDIA) cohort. ${ }^{3}$ We now investigate whether genetic variation in GSTP1, GSTM1 and GSTT1 modifies the association of BHR with the development of asthma. In particular, a GSTP1 Ile/Val single nucleotide polymorphism at the amino acid residue 105 results in different enzymatic efficiency. ${ }^{15}$ GSTP1 $105 \mathrm{Val}$ heterozygous or homozygous carriers have been shown to experience a protective effect against asthma ${ }^{16}$ and atopic airway inflammation. ${ }^{17}$ We therefore hypothesised that the risk of an increasing effect of BHR would be stronger among homozygous GSTP1 105 Ile carriers and sought to answer this question in a large population-based study.

\section{METHODS}

\section{Study population}

The SAPALDIA cohort, a prospective multicentre study representative of the adult Swiss general population, investigates environmental and genetic factors determining lung health. Baseline and follow-up examinations 11 years later have previously been described in detail. ${ }^{18} 19$

Briefly, 9561 subjects predominantly of European Caucasian ethnicity aged 18-60 years were examined at baseline in 1991. Of these, 8047 $(84 \%)$ agreed to participate fully or partly at the follow-up survey in 2002. Information on health and life style was collected by computer-assisted personal interview at both time points and lung function was evaluated using the same spirometer devices (Sensormedics model 2200, Yorba Linda, USA) at both time points. ${ }^{20}$ Skin reactivity to eight 
common airborne allergens was assessed by skin prick test at baseline. Circulating serum levels of total IgE and Phadiatop test for detection of allergen-specific IgE were measured at baseline using the CAP FEIA system (Pharmacia Diagnostics, Uppsala, Sweden). Blood for DNA extraction and informed consent to genetic testing was collected at follow-up.

\section{Methacholine challenge}

BHR was assessed by methacholine challenge (Provocholine, Roche, Nutley, New Jersey, USA) in 7126 participants at baseline. Increasing concentrations of methacholine $(0.39,1.56$, 6.25 and $25.0 \mathrm{mg} / \mathrm{ml}$ solutions in a phosphate buffer without phenol) were administered through an aerosol dosimeter (Mefar MB3, Bovezzo, Italy). ${ }^{21}$ The presence of BHR was defined as a fall of $\geqslant 20 \%$ in forced expiratory volume in $1 \mathrm{~s}\left(\mathrm{FEV}_{1}\right)$ up to a cumulative dose of $2 \mathrm{mg}(8.37 \mu \mathrm{mol})$. The methacholine responsiveness was determined for each subject by calculating individual dose-response slopes similar to the method suggested by O'Connor et al. ${ }^{22}{ }^{23}$ The slope was then defined as the ratio between the percentage decline in $\mathrm{FEV}_{1}$ and the total cumulative dose of methacholine.

\section{Definition of asthma incidence, respiratory symptoms and selected covariates}

Incident asthma cases were defined as new asthma reports when participants without asthma at baseline gave a positive answer at follow-up to the following two questions: "Have you ever had asthma?" and "Was this confirmed by a doctor?".

Current asthma symptoms were defined by a self-report of physician-diagnosed asthma and a positive answer to at least one of the following questions: "Are you currently taking any medicine for asthma?" and "Have you had an attack of asthma in the last 12 months?".

Atopy was defined as a positive skin prick test reaction to at least one common allergen tested. ${ }^{24}$ Occupational exposure to inhalant irritants was assessed by asking: "Have you ever worked in a job which exposed you to vapours, gas, dust or fumes?". Smokers were participants who had smoked $\geqslant 20$ packs of cigarettes or $\geqslant 360 \mathrm{~g}$ of tobacco in their lifetime. ${ }^{18} 1925$ Former smokers at baseline or follow-up were smokers who had quit smoking at least 1 month before the examination. Current smokers reported active smoking at the interview. The amount of cigarette exposure of participants was assessed by pack-years. Environmental tobacco smoke (ETS) was defined by a positive answer to the question: "Have you been regularly exposed to tobacco smoke in the last 12 months? "regularly" means on most days or nights)?".

\section{Genotyping}

Whole blood was sampled at follow-up and DNA was extracted manually ${ }^{19}$ using the Gentra Puregene Kit (Gentra Systems, Minneapolis, USA). Genotyping of the GSTP1 Ile105Val single nucleotide polymorphism and the gene deletion polymorphisms for GSTM1 and GSTT1 was performed by TaqMan methodology as previously described. ${ }^{12}$ Hardy-Weinberg equilibrium (HWE) for the GSTP1 Ile105Val polymorphism was tested using Arlequin Version $2.000^{26}$ and genotype distribution was found to be in HWE. Genotype frequencies did not differ by Swiss language region or subjects' nationality.

\section{Study sample}

We included in the present analysis SAPALDIA participants with valid spirometric and bronchial challenge data from the baseline examination and questionnaire data who participated in the interview at follow-up $(n=5825$; see fig 1 in online supplement). Valid information on respiratory health status at baseline and follow-up as well as genotype information on the GST polymorphisms were available for 4682 of these participants. Subjects who had reported physician-diagnosed asthma at baseline were excluded $(n=256)$. The final sample size for this study consisted of 4426 SAPALDIA participants. Missing information for the covariates baseline forced vital capacity (FVC) $(n=105)$, atopy $(n=99)$, pack-years smoked during follow-up $(n=112)$, ETS exposure $(n=5)$ and occupational inhalant exposure $(n=332)$ reduced the study sample available for multiple regression analysis to 3806 subjects, of which $3.1 \%$ reported physician-diagnosed asthma for the first time at follow-up $(n=119)$.

\section{Statistical analysis}

Differences in genotype frequency between cases and controls were assessed by $\chi^{2}$ test. The associations between GST genotypes and bronchoconstrictor response slope measured as the percentage fall in $\mathrm{FEV}_{1}$ per $\mu \mathrm{mol}$ methacholine at baseline were assessed by multiple linear regression adjusting for baseline information on $\mathrm{FEV}_{1}, \mathrm{FEV}_{1}$ squared, study area, sex, age, body mass index (BMI), atopy, smoking status and pack-years smoked; predicted values for GSTP1 Ile105Val genotypes were displayed using the box plot command. The effects of BHR at baseline and GST genotypes on the risk for reporting new physician-diagnosed asthma and current asthma symptoms at follow-up were estimated using multiple logistic regression analysis adjusted for sex, age, study area, baseline measures of FVC and BMI, weight change during follow-up, and follow-up information on smoking status, amount of pack-years smoked, and exposure to ETS, occupational dust, fumes and vapours. Modification of the effect of baseline BHR on incident asthma reports by GSTP1 Ile105Val genotype was assessed by including a multiplicative interaction term in the model, as well as by stratifying the analysis by genotype. Cumulative asthma incidences with $95 \%$ confidence intervals (CI) in subgroups defined by combinations of GSTP1 Ile105Val genotypes and baseline BHR were calculated using the adjust command after multivariate logistic regression analysis. Two-sided $p$ values of $<0.05$ and $<0.10$ were considered statistically significant for main effects and interactions. ${ }^{27}$ All analyses were conducted using STATA SE Version 9.1 (Stata Corporation, Texas, USA).

\section{RESULTS}

The characteristics of the study population overall and stratified by the presence or absence of baseline BHR are shown in table 1. Among the 4426 participants free of asthma at baseline, 3.3\% $(n=144)$ reported a history of physician-diagnosed asthma at the follow-up examination.

Of the study sample, $14 \%$ had BHR at baseline; women were overrepresented in the group exhibiting BHR. Lung function was lower and the proportion of subjects with $\mathrm{FEV}_{1} / \mathrm{FVC}<0.70$ was higher in the subgroup with BHR. Smokers were more likely to have BHR and the mean amount of pack-years smoked was higher in subjects with BHR, whereas no difference in ETS exposure or occupational exposure to gas, dust and fumes was noted between the two BHR groups. Baseline respiratory symptoms such as wheezing, chronic cough and phlegm and shortness of breath at night were more prevalent in the group with BHR; $19.7 \%$ of subjects with BHR reported at least one respiratory symptom compared with only $11.5 \%$ of participants 
Table 1 Characteristics* of the study population overall and stratified by the presence or absence of baseline BHR

\begin{tabular}{llll}
\hline & All & Without BHR & With BHR \\
\hline Cohort participants included in study, N (\%) & $4426(100)$ & $3800(85.9)$ & $626(14.1)$ \\
Women, N (\%) & $2169(49.0)$ & $1758(46.3)$ & $411(66.7)$
\end{tabular}

\begin{tabular}{|c|c|c|c|}
\hline \multicolumn{4}{|l|}{ Baseline characteristics } \\
\hline Mean (SD) age at baseline (years) & $40.5(11.3)$ & $40.3(11.2)$ & $41.4(11.7)$ \\
\hline BMI at baseline $\left(\mathrm{kg} / \mathrm{m}^{2}\right)$ & $23.7(3.5)$ & $23.6(3.4)$ & $23.9(4.0)$ \\
\hline Total lgE $>100 \mathrm{kU} / \mathrm{l}, \mathrm{N}(\%)$ & $821(20.1)$ & $657(18.6)$ & $164(29.3)$ \\
\hline Atopy, N (\%) & $908(21.0)$ & $680(19.6)$ & $159(28.0)$ \\
\hline Geometric mean (SD) methacholine response slope§ & $1.0(3.7)$ & $0.7(2.9)$ & $7.1(2.8)$ \\
\hline Non-smokers, N (\%) & $2069(46.8)$ & $1780(46.9)$ & $289(46.3)$ \\
\hline Former smokers, $\mathrm{N}(\%)$ & $1016(23.0)$ & $900(23.7)$ & $116(18.6)$ \\
\hline Current smokers, N (\%) & $1337(30.2)$ & $1118(29.4)$ & $219(35.1)$ \\
\hline Mean (SD) pack-years among ever smokers at baseline & $16.5(17.7)$ & $16.0(17.3)$ & $19.7(19.6)$ \\
\hline ETS exposure reported at baseline, $\mathrm{N}(\%)$ & $879(19.9)$ & $757(19.9)$ & $122(19.6)$ \\
\hline Gas, fumes and dust exposure at work at baseline, N (\%) & $1348(30.6)$ & $1144(30.2)$ & $204(32.6)$ \\
\hline Mean (SD) FEV $1 \%$ pred) & $101.6(12.2)$ & $102.7(11.8)$ & $94.7(12.1)$ \\
\hline Mean (SD) FVC (I) & $4.6(1.0)$ & $4.7(1.0)$ & $4.2(1.0)$ \\
\hline Mean (SD) FEV $1 / F V C$ (\%) & $79.8(6.8)$ & $80.2(6.6)$ & $77.3(7.2)$ \\
\hline $\mathrm{FEV}_{1} / \mathrm{FVC}<0.7, \mathrm{~N}(\%)$ & $324(7.5)$ & $232(6.3)$ & $92(15.0)$ \\
\hline Wheezing without cold in last 12 months, $\mathrm{N}(\%)$ & $207(4.7)$ & $149(3.9)$ & $58(9.3)$ \\
\hline Chronic phlegm, N (\%) & $222(5.1)$ & $181(4.8)$ & $41(6.7)$ \\
\hline Chronic cough, N (\%) & $157(3.6)$ & $119(3.1)$ & $38(6.1)$ \\
\hline Woken up at night by shortness of breath, $\mathrm{N}(\%)$ & $117(2.6)$ & $94(2.5)$ & $23(3.7)$ \\
\hline$\geqslant 1$ of respiratory symptoms above, $\mathrm{N}(\%)$ & $561(12.7)$ & $438(11.5)$ & $123(19.7)$ \\
\hline \multicolumn{4}{|l|}{ Selected follow-up characteristics } \\
\hline BMI at follow-up $\left(\mathrm{kg} / \mathrm{m}^{2}\right)$ & $25.7(4.2)$ & $25.7(4.1)$ & $26.1(4.9)$ \\
\hline Mean (SD) weight change during follow-up (kg) & $5.6(6.1)$ & $5.5(6.1)$ & $5.7(6.3)$ \\
\hline Never smokers, $\mathrm{N}(\%)$ & $1905(43.0)$ & $1631(43.0)$ & $267(43.0)$ \\
\hline Ever smokers, $\mathrm{N}(\%)$ & $2521(57.0)$ & $2164(57.0)$ & $357(57.0)$ \\
\hline Mean (SD) pack-years $₫$ & $6.1(7.6)$ & $6.0(7.6)$ & $7.0(7.8)$ \\
\hline ETS exposure reported at follow-up, N (\%) & $585(13.2)$ & $507(13.3)$ & $78(12.5)$ \\
\hline Gas, fumes and dust exposure at work at follow-up, N (\%) & $1143(27.9)$ & $1013(28.7)$ & $130(22.9)$ \\
\hline \multicolumn{4}{|l|}{ GST genotypes } \\
\hline \multicolumn{4}{|l|}{ GSTP1 Ile105Val, N (\%) } \\
\hline Ile/lle & $2071(46.8)$ & $1792(47.2)$ & $253(44.6)$ \\
\hline Ile/Val & $1945(43.9)$ & $1650(43.4)$ & $266(46.9)$ \\
\hline $\mathrm{Val} / \mathrm{Val}$ & $410(9.3)$ & $358(9.4)$ & $48(8.5)$ \\
\hline Ile/Val or $\mathrm{Val} / \mathrm{Val}$ & $2355(53.2)$ & $1828(52.5)$ & $314(55.4)$ \\
\hline \multicolumn{4}{|l|}{ GSTM1, N (\%) } \\
\hline No homozygous deletion & $2100(47.5)$ & $1802(47.5)$ & $298(47.7)$ \\
\hline Homozygous deletion & $2322(52.5)$ & $1995(52.5)$ & $327(52.3)$ \\
\hline \multicolumn{4}{|l|}{ GSTT1, N (\%) } \\
\hline No homozygous deletion & $3600(81.4)$ & $3090(81.4)$ & $510(81.6)$ \\
\hline Homozygous deletion & $822(18.6)$ & $707(18.6)$ & 115 (18.4) \\
\hline
\end{tabular}

without BHR. The GST genotype distributions agreed well with those previously reported in other Caucasian populations..$^{13} 1628$

Earlier reports suggested that GSTP1 genotype might be associated with BHR. ${ }^{16}$ Table 1 shows that the distribution of the various GSTP1 Ile105Val genotypes was not materially different among participants with or without BHR. Homozygous Ile carriers were slightly underrepresented among subjects with baseline BHR but the difference did not reach statistical significance $(44.6 \%$ vs $47.2 \%, p=0.23$; table 1$)$. We also compared the adjusted methacholine dose response according to GST genotypes (fig 1). No difference in response to the bronchoconstrictor was observed between the three GSTP1 Ile105Val genotypes. GSTM1 and GSTT1 genotypes were not associated with response to methacholine (data not shown). Homozygous GSTP1 Ile/lle genotypes were slightly overrepresented among subjects with asthma at baseline $(p=0.06)$. Neither GSTM1 nor GSTT1 genotype was associated with selfreported physician-diagnosed asthma at baseline (see table 1 in online supplement). 


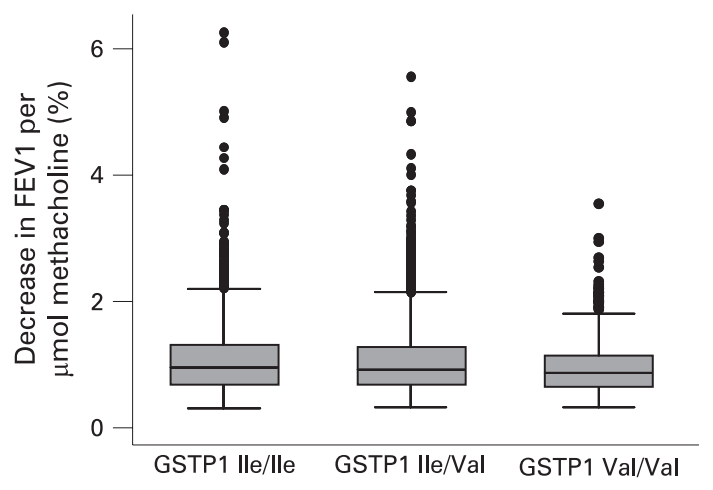

Figure 1 Distribution of predicted adjusted baseline methacholine dose-response slope in relation to GSTP1 genotype (adjusted for area, sex, age, baseline information on forced expiratory volume in $1 \mathrm{~s}\left(\mathrm{FEV}_{1}\right)$, $\mathrm{FEV}_{1}$ squared, body mass index, atopy, smoking status and pack-years smoked.

In table 2 we present the unadjusted association of both GST genotypes and baseline BHR with physician-diagnosed asthma at follow-up. Both baseline BHR and GSTP1 Ile105Val genotype-but not GSTM1 or GSTT1 gene deletion polymorphisms-were associated with new asthma reports at follow-up $(\mathrm{p}<0.001$ for baseline BHR and $\mathrm{p}=0.005$ for GSTP1 genotype) The independent associations of baseline BHR and GSTP1 genotype with physician-diagnosed asthma at follow-up were confirmed after adjustment for potential confounders and mutual adjustment for each other (fig 2). The adjusted odds ratio (OR) for BHR vs no BHR was 3.52 (95\% CI 2.31 to 5.35; $\mathrm{p}<0.001)$ and for GSTP1 105Ile/Ile vs GSTP1 105Val genotypes it was 1.71 (95\% CI 1.17 to $2.50 ; \mathrm{p}=0.006)$.

The BHR effect on new reports of asthma and asthma symptoms was modified by GSTP1 (table 3). The effect of baseline BHR on the risk for new reports of asthma was stronger for the GSTP1 Ile/Ile genotype (OR 4.84 (95\% CI 2.28 to 8.49 ) vs 2.42 ( $95 \%$ CI 1.25 to 4.67); p for interaction between BHR and GSTP1 Ile105Val genotype $\left.\mathrm{P}_{\mathrm{BHR}}{ }^{*} \mathrm{GSTP}_{1}=0.117\right)$. The effect modification by GSTP1 genotype reached statistical significance after exclusion of subjects reporting at least one respiratory symptom at baseline (OR 4.57 (95\% CI 2.43 to 8.57) vs 1.40 (95\% CI 0.58 to 3.39); p $\left._{\text {BHR }}{ }^{*} G S T P 1=0.023\right)$. Comparable interactions between GSTP1 genotype and baseline BHR were observed for self-reported asthma symptoms at follow-up. Again, the BHR effect was stronger in homozygous GSTP1

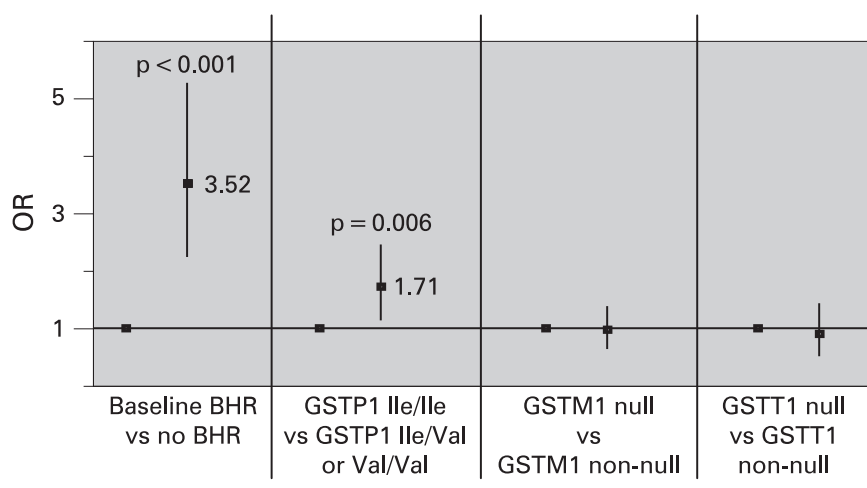

Figure 2 Adjusted risk for self-report of physician-diagnosed asthma in relation to baseline bronchial hyperresponsiveness (BHR) as well as GSTP1 lle105Val, GSTM1 or GSTT1 gene deletion polymorphisms (adjusted for baseline forced vital capacity, body mass index, age, sex, study area, weight change during follow-up, smoking status at follow-up, pack-years smoked to follow-up, environmental tobacco smoke exposure at follow-up, occupational gas/dust/fume exposure at follow-up. BHR effect additionally adjusted for the three GST genotypes; GST genotype effects additionally adjusted for baseline BHR.

Ile/Ile genotypes than in GSTP1 105Val carriers and reached statistical significance after exclusion of subjects reporting at least one respiratory symptom at baseline (OR 15.86 (95\% CI 5.32 to 47.26$)$ vs 1.95 (95\% CI 0.71 to 6.96$\left.) ; \mathrm{p}_{\mathrm{BHR}^{*}{ }_{G S T P 1}}=0.033\right)$. No modification of the BHR/asthma association by GSTT1 or GSTM1 gene deletion was observed (data not shown).

The adjusted 11-year cumulative incidence of self-reported physician-diagnosed asthma was 14 cases per 1000 persons (95\% CI 9 to 21) among subjects without baseline BHR and no GSTP1 Ile/Ile genotype; 19 cases per 1000 (95\% CI 13 to 28) among subjects without BHR but with GSTP1 Ile/Ile genotype; 21 cases per 1000 (95\% CI 9 to 45) among subjects with BHR and no GSTP1 Ile/Ile genotype; and 95 cases per 1000 (95\% CI 59 to 150) among subjects with both baseline BHR and GSTP1 105Ile/Ile genotype. Thus, among participants with baseline BHR in this study population, the excess number of incident asthma cases due to GSTP1 Ile/Ile genotype was 74/1000 persons over the 11-year follow-up period.

Since GST genotypes have previously been associated with lung growth in children ${ }^{10}$ and with lung function in adults, ${ }^{12}{ }^{14}$ we performed a sensitivity analysis and omitted the adjustment for baseline lung function from all statistical models. None of the effects presented were materially altered (data not shown).

Table 2 Unadjusted association of baseline BHR and GST genotypes with self-report of physician-diagnosed asthma after 11 years of follow-up

\begin{tabular}{lccc}
\hline & $\begin{array}{l}\text { Subjects at risk } \\
\text { at baseline }(\mathbf{n})\end{array}$ & New asthma reports & p Value for difference \\
\hline $\begin{array}{l}\text { Baseline BHR } \\
\text { Without BHR }\end{array}$ & 3800 & $94 / 2.5 \%$ & \\
$\quad$ With BHR & 626 & $50 / 8.0 \%$ & $<0.001$ \\
$\begin{array}{l}\text { GSTP1 lle105Val } \\
\text { Ile/Nal or Val/Nal }\end{array}$ & 2355 & $60 / 2.6 \%$ & \\
Ile/lle & 2071 & $77 / 4.0 \%$ & 0.005 \\
GSTM1 & & & \\
No deletion & 2100 & $71 / 3.4 \%$ & 0.66 \\
$\quad$ Deletion & 2322 & $73 / 3.1 \%$ & \\
GSTT1 & & & \\
No deletion & 3600 & $119 / 3.3 \%$ & 0.70 \\
Deletion & 822 & $25 / 3.0 \%$ & \\
\hline
\end{tabular}

BHR, bronchial hyperresponsiveness; GST, glutathione S-transferase. 
Table 3 Adjusted risk* for self-reported physician-diagnosed asthma and asthma symptoms at follow-up in relation to bronchial hyperresponsiveness (BHR) at baseline, stratified by GSTP1 lle105Val genotype

\begin{tabular}{|c|c|c|c|c|c|c|c|c|c|}
\hline & \multicolumn{4}{|c|}{ GSTP1 Ile/lle } & \multicolumn{4}{|c|}{ GSTP1 Ile/Val or Val/Nal } & \multirow{2}{*}{$\begin{array}{l}\text { Interaction } \\
\text { p Value: }\end{array}$} \\
\hline & $\begin{array}{l}\text { Subjects } \\
\text { at risk }\end{array}$ & Cases & OR $(95 \% \mathrm{CI})$ & p Value & $\begin{array}{l}\text { Subjects } \\
\text { at risk }\end{array}$ & Cases & OR $(95 \% \mathrm{CI})$ & p Value & \\
\hline \multicolumn{10}{|c|}{ Physician-diagnosed asthma } \\
\hline Without BHR & 1551 & 42 & 1 & & 1729 & 35 & 1 & & \\
\hline With BHR & 232 & 27 & $4.84(2.28$ to 8.49$)$ & $<0.001$ & 294 & 15 & 2.42 (1.25 to 4.67$)$ & 0.009 & 0.117 \\
\hline \multicolumn{10}{|c|}{ Current asthma symptoms } \\
\hline Without BHR & 1551 & 10 & 1 & & 1729 & 13 & 1 & & \\
\hline With BHR & 232 & 16 & $14.7(5.76$ to 37.36$)$ & $<0.001$ & 294 & 9 & $4.06(1.59$ to 10.40$)$ & 0.003 & 0.115 \\
\hline
\end{tabular}

\begin{tabular}{|c|c|c|c|c|c|c|c|c|c|}
\hline \multicolumn{10}{|c|}{ Physician-diagnosed asthma } \\
\hline Without BHR & 1384 & 37 & 1 & & 1524 & 30 & 1 & & \\
\hline With BHR & 186 & 21 & 4.57 (2.43 to 8.57$)$ & $<0.001$ & 236 & 7 & $1.40(0.58$ to 3.39$)$ & 0.45 & 0.023 \\
\hline \multicolumn{10}{|c|}{ Current asthma symptoms } \\
\hline Without BHR & 1384 & 9 & 1 & & 1524 & 12 & 1 & & \\
\hline With BHR & 186 & 11 & $15.86(5.32$ to 47.26$)$ & $<0.001$ & 236 & 4 & $1.95(0.71$ to 6.96$)$ & 0.29 & 0.033 \\
\hline
\end{tabular}

\footnotetext{
*Adjusted for baseline measures of forced vital capacity and body mass index, weight change during follow-up, sex, age, smoking status (never/persistent/others), pack-years smoked to follow-up, environmental tobacco smoke (follow-up) and occupational dust/fumes/vapour exposure (follow-up), study area.

$\uparrow$ Subjects excluded $(n=476)$ who reported at baseline at least one of the following respiratory symptoms: wheezing without a cold; chronic cough; chronic phlegm; woken up by shortness of breath at night.

łp Values for interaction between bronchial hyperresponsiveness (BHR) and GSTP1 Ile105Val genotype obtained by including multiplicative interaction term in multiple logistic
} regression analysis.

\section{DISCUSSION}

We present evidence that adults with BHR and GSTP1 Ile/Ile genotype are at an increased risk of developing asthma. Furthermore, genetic variation in GSTP1 (but not GSTM1 or GSTT1) modifies the risk of BHR progression to asthma in the general population. As GSTP1 exhibits the highest lung tissue expression of the three GST enzymes, our results are in line with the hypothesis that the extent of local inflammation in the airways contributes to airway remodelling and thus to the association between BHR and adult onset asthma.

Airway smooth muscle dysfunction ${ }^{29-31}$ and increased airway wall thickening ${ }^{32}$ caused by airway remodelling are commonly thought to underlie BHR and possibly its progression to asthma. Prolonged or repeated exposure to airway irritants (such as tobacco smoke, ambient air pollution or occupational activityderived particles) can cause airway dysfunction of the smooth muscle and the bronchial epithelium through the induction of chronic airway inflammation. ${ }^{21} 34{ }^{35}$ BHR itself contributes to a harmful circle of sustained inflammation since the associated abnormal airflow resulting from the reduced airway calibre alters the deposition profile of inhalants in the airways. ${ }^{36-39}$ It therefore seems probable that increased depositions of particles with mostly oxidative properties will result in sustained airway inflammation and oxidative stress. This view is corroborated by recent SAPALDIA results showing that BHR increased the effect of ETS exposure on the incidence of asthma-related symptoms. ${ }^{3}{ }^{40}$

According to our results, the genetic make-up of a person codetermines the exposure load necessary to induce sustained inflammation, oxidative stress and airway remodelling in the bronchial tissue. The modifying effect of the GSTP1 Ile105Val genotype may reflect the different (but related) roles of this enzyme (ie, in phase II detoxification of tobacco- or air pollution-derived chemicals, ${ }^{7}$ in oxidant defence ${ }^{41}$ and in cell cycle regulation ${ }^{42}$ ). Lower GSTP1 activity in bronchial tissue is likely to result in decreased detoxification of airway irritants, enhanced inflammation and oxidative stress causing sustained airway wall thickening and smooth muscle dysfunction. This hypothesised pathophysiological mechanism is supported by evidence for the direct involvement of GSTP1 in the regulation of C-JUN N-terminal protein kinase (JNK) and downstream processes which lead to increased cell proliferation in response to oxidative stress. ${ }^{43} 44$ Mice deficient for GSTP1 activity are prone to increased tumorigenesis on exposure to polycylic hydrocarbons. ${ }^{45}$ The modifying effect of GSTP1 in the BHR/ asthma association may therefore result from the central role of this enzyme and oxidative stress in apoptotic processes.

Previous evidence supports the hypothesis that the degree of airway inflammation and oxidative stress contributes to the progression of BHR. First, in utero exposure to maternal smoking increases the risk of progression from BHR to asthma. ${ }^{46}$ Passive smoking has been shown to confer increased oxidative stress locally in bronchial tissue as well as systemically in exposed subjects. ${ }^{47-49}$ Second, obesity characterised by increased systemic inflammation has been associated with increased progression of BHR and asthma. ${ }^{31}$ Third, Cheng et al ${ }^{50}$ found a gradient of free radical concentrations in nasal polyps, an inflammatory chronic disease frequently associated with BHR and asthma. Concentrations were lowest in cases with nasal polyps without BHR and asthma, intermediate in those with concurrent silent BHR and highest in cases of nasal polyps with concurrent BHR and asthma.

Genetic GST variants have previously been associated with asthma in different, exclusively cross-sectional, studies. The prevalence of the GSTP1 $105 \mathrm{Val}$ allele was lower in patients with asthma, ${ }^{51} 52 \mathrm{BHR}^{16}$ and asthmatics with severe disease. ${ }^{16} 175354$ Our findings extend this observation and indicate that the GSTP1 105Ile/Ile genotype, which is carried by about $47 \%$ of our European Caucasian population, represents a prevalent asthma risk factor in the general adult population. The absence of a cross-sectional GSTP1/BHR association in our population-based study contrasts with the positive association found by Fryer and colleagues. ${ }^{16}$ Their study recruited volunteers and patients from respiratory clinics. Female subjects were overrepresented (>70\%). Women are known to be more susceptible to bronchoconstrictor challenge ${ }^{1623}$ although, in 
the SAPALDIA cohort, the GSTP1/BHR association was not modified by gender (data not shown). Our finding of a lack of association between GSTM1 and GSTT1 gene deletion and the occurrence of asthma also contrasts with some previous results. A few small case-control studies suggest that the prevalence of GSTM1 and GSTT1 gene deletions is increased in patients with asthma with concurrent atopy. ${ }^{55} 56$ In a limited number of cohorts, GSTM1 and GSTT1 deficiency increased the risk for asthma, asthma-related symptoms and low lung function during childhood in combination with in utero and/or current passive smoking exposure. ${ }^{10}{ }^{1157}$ Protective effects of antioxidant supplementation on the lung function of children with asthma exposed to high ambient ozone were restricted to GSTM1deficient participants. ${ }^{58}$ The discrepancy between our study and previous reports with regard to the role of GSTM1 and GSTT1 deletions might partly be related to differences in study population, sample size, study design or inhalant exposures. Most importantly, we focused on adult incident asthma whereas the evidence for an association between asthma and GSTM1 or GSTT1 was most consistently found in children. Unfortunately, our sample size was insufficient to additionally stratify the results by atopy or exposure to environmental inhalants including ETS.

The strength of the present study is its prospective design which allowed us to investigate the long-term effects of BHR in the general population. The large sample size of the cohort and its detailed characterisation made it possible to investigate the interaction between BHR and GST genotypes on the incidence of adult onset asthma. In addition, it was possible to refine the analysis after exclusion of participants who might have had asthma symptoms at baseline without the formal diagnosis of asthma. Nevertheless, the number of new asthma cases available to estimate the effect modification of baseline BHR by the GSTP1 genotype was limited. Independent studies are therefore needed to confirm this novel finding.

The definition of asthma in the present study relied solely on the self-report of asthma phenotypes. Asthma status may therefore be subject to misclassification. ${ }^{5960}$ The unknown degree of population stratification is another limitation, as no panel of anonymous markers was tested to assay the population admixture of the Swiss general population. However, stratification of the associations by study centre, language region and nationality did not materially alter the main findings, suggesting only a minor influence of population stratification at best. We cannot exclude participation bias. Participants at baseline were less likely to be of intermediate age or of Swiss nationality, but were more likely to be former smokers and to report asthma or wheezing than non-participants. ${ }^{18} 19$ Unlike participation at baseline, patients with asthma were less likely to participate at follow-up. ${ }^{319}$ Among the non-participants at the follow-up examination there were slightly more men, smokers, subjects with low educational background, subjects with occupational exposure to fumes, gas and dust, and with respiratory symptoms. No difference was noted for atopy and BHR between participants and non-participants at follow-up. Subjects with low lung function-a risk factor for $\mathrm{BHR}^{61}$ were less likely to undergo methacholine challenge, ${ }^{3}$ but we had previously presented results from the SAPALDIA cohort which showed that, in contrast to previous evidence, ${ }^{14}$ GSTP1 was not associated with lung function in this adult sample from the general population..$^{12}$ In the absence of genotype information on non-participants at baseline and follow-up, we cannot analyse whether we failed to include subjects with unique genotype/ phenotype combinations. Even though it is unlikely that genotype status influenced participation, this possible source of bias also points to the need for independent studies to confirm our result.

In conclusion, we present evidence that the GSTP1 Ile/Ile genotype may be a strong and prevalent risk factor for the progression of silent BHR to asthma in the general population. If confirmed by additional studies, the results are consistent with the hypothesis that genetic variation in the local metabolism of inhalant-derived chemicals and/or free radicals plays a relevant role in the progression from BHR to asthma.

Acknowledgements: The study could not have been done without the help of the study participants, technical and administrative support, the medical teams and field workers at the local study sites as well as the entire SAPALDIA Team. The authors also thank Esther Glaus for extracting the DNA and Dr med Oliver Senn for genotyping.

Funding: This research has been supported by the Swiss National Science Foundation (grants no 4026-28099, 3347C0-108796, 3247B0-104283, 3247B0-104288, 3247B0104284, 32-65896.01, 32-59302.99, 32-52720.97, 32-4253.94), the Federal Office for Forest, Environment and Landscape, the Federal Office of Public Health, the Federal Office of Roads and Transport, the canton's government of Aargau, Basel-Stadt, BaselLand, Geneva, Luzern, Ticino, Zurich, the Swiss Lung League, the canton's Lung League of Basel Stadt/Basel Landschaft, Geneva, Ticino and Zurich and Freiwillige Akademische Gesellschaft, Basel.

\section{Competing interests: None.}

Ethics approval: Ethical approval for the study was given by the central ethics committee of the Swiss Academy of Medical Sciences and the Cantonal ethics committees for each of the eight examination areas.

Local field workers: Aarau: M Broglie, M Bünter, D Gashi; Basel: R Armbruster, T Damm, U Egermann, M Gut, L Maier, A Vögelin, L Walter; Davos: D Jud, N Lutz; Geneva: M Ares, M Bennour, B Galobardes, E Namer; Lugano: B Baumberger, S Boccia Soldati, E Gehrig-Van Essen, S Ronchetto; Montana: C Bonvin, C Burrus; Payerne: S Blanc, AV Ebinger, M L Fragnière, J Jordan; Wald: R Gimmi, N Kourkoulos, U Schafroth. Administrative staff: N Bauer, D Baehler, C Gabriel, R Nilly.

SAPALDIA Team: Study directorate: T Rochat (p), U Ackermann-Liebrich (e), J M Gaspoz (c), P Leuenberger (p), LJS Liu (exp), NM Probst Hensch (e/g), C Schindler (s). Scientific team: J C Barthélémy (c), W Berger (g), R Bettschart (p), A Bircher (a), G Bolognini (p), 0 Brändli (p), M Brutsche (p), L Burdet (p), M Frey (p), MW Gerbase (p), D Gold (e/c/p), W Karrer (p), R Keller (p), B Knöpfli (p), N Künzli (e/exp), U Neu (exp), L Nicod (p), M Pons (p), E Russi (p), P Schmid-Grendelmeyer (a), J Schwartz (e), P

Straehl (exp), JM Tschopp (p), A von Eckardstein (cc), J P Zellweger (p), E Zemp Stutz (e). Scientific team at coordinating centres: P O Bridevaux (p), I Curjuric (e), S H Downs (e/s), D Felber Dietrich (c), A Gemperli (s), D Keidel (s), M Imboden (g), P Staedele-Kessler (s), G A Thun (g). [(a) allergology, (c) cardiology, (cc) clinical chemistry, (e) epidemiology, (exp) exposure, (g) genetic and molecular biology, (m) meteorology, (p) pneumology, (s) statistics]

\section{REFERENCES}

1. Grootendorst DC, Rabe KF. Mechanisms of bronchial hyperreactivity in asthma and chronic obstructive pulmonary disease. Proc Am Thorac Soc 2004;1:77-87.

2. Laprise $\mathbf{C}$, Laviolette $\mathrm{M}$, Boutet $\mathrm{M}$, et al. Asymptomatic airway hyperresponsiveness: relationships with airway inflammation and remodelling. Eur Respir J 1999;14:63-73.

3. Brutsche MH, Downs SH, Schindler C, et al. Bronchial hyperresponsiveness and the development of asthma and COPD in asymptomatic individuals: SAPALDIA cohort study. Thorax 2006;61:671-7.

4. Sistek D, Wickens K, Amstrong R, et al. Predictive value of respiratory symptoms and bronchial hyperresponsiveness to diagnose asthma in New Zealand. Respir Med 2006;100:2107-11.

5. $\mathbf{X u} \mathbf{X}$, Rijcken B, Schouten JP, et al. Airways responsiveness and development and remission of chronic respiratory symptoms in adults. Lancet 1997;350:1431-4.

6. Southam DS, Ellis R, Wattie J, et al. Components of airway hyperresponsiveness and their associations with inflammation and remodeling in mice. J Allergy Clin Immunol 2007;119:848-54.

7. Strange RC, Spiteri MA, Ramachandran S, et al. Glutathione-S-transferase family of enzymes. Mutat Res 2001;482:21-6.

8. Hayes JD, Strange RC. Potential contribution of the glutathione S-transferase supergene family to resistance to oxidative stress. Free Radic Res 1995;22:193-207.

9. Fryer AA, Hume R, Strange RC. The development of glutathione S-transferase and glutathione peroxidase activities in human lung. Biochim Biophys Acta 1986;883:448-53.

10. Gilliland FD, Gauderman WJ, Vora H, et al. Effects of glutathione-S-transferase M1, $\mathrm{T} 1$, and P1 on childhood lung function growth. Am J Respir Crit Care Med 2002;166:710-6. 
11. Gilliland FD, Rappaport EB, Berhane K, et al. Effects of glutathione S-transferase P1, $\mathrm{M} 1$, and T1 on acute respiratory illness in school children. Am J Respir Crit Care Med 2002;166:346-51.

12. Imboden M, Downs SH, Senn 0, et al. Glutathione S-transferase genotypes modify lung function decline in the general population: SAPALDIA cohort study. Respir Res 2007;8:2.

13. He Ja, Ruan J, Connett JE, et al. Antioxidant gene polymorphisms and susceptibility to a rapid decline in lung function in smokers. Am J Respir Crit Care Med 2002;166:323-8.

14. He JQ, Connett JE, Anthonisen NR, et al. Glutathione S-transferase variants and their interaction with smoking on lung function. Am J Respir Crit Care Med 2004;170:38894.

15. Hayes JD, Strange RC. Glutathione S-transferase polymorphisms and their biological consequences. Pharmacology 2000;61:154-66.

16. Fryer AA, Bianco A, Hepple $\mathrm{M}$, et al. Polymorphism at the glutathione S-transferase GSTP1 locus. A new marker for bronchial hyperresponsiveness and asthma. Am J Respir Crit Care Med 2000;161:1437-42.

17. Spiteri MA, Bianco A, Strange RC, et al. Polymorphisms at the glutathione Stransferase, GSTP1 locus: a novel mechanism for susceptibility and development of atopic airway inflammation. Allergy 2000;55(Suppl 61):15-20.

18. Martin BW, Ackermann-Liebrich U, Leuenberger P, et al. SAPALDIA: methods and participation in the cross-sectional part of the Swiss Study on Air Pollution and Lung Diseases in Adults. Soz Praventivmed 1997:42:67-84.

19. Ackermann-Liebrich U, Kuna-Dibbert B, Probst-Hensch N, et al. Follow-up of the Swiss Cohort Study on Air Pollution and Lung Diseases in Adults (SAPALDIA 2) 19912003: methods and characterization of participants. Soz Praventiv Med 2005;50:24563.

20. Kunzli N, Kuna-Dibbert B, Keidel D, et al. Longitudinal validity of spirometers - a challenge in lung function follow-up studies. Swiss Medical Weekly 2005;135:503-8.

21. Leuenberger $\mathbf{P}$, Schindler C, Schwartz J, et al. Occupational exposure to inhalative irritants and methacholine responsiveness. Scand J Work Environ Health 2000:26:146-52.

22. O'Connor G, Sparrow D, Taylor D, et al. Analysis of dose-response curves to methacholine. An approach suitable for population studies. Am Rev Respir Dis 1987; 136:1412-7.

23. Schwartz J, Schindler C, Zemp E, et al. Predictors of methacholine responsiveness in a general population. Chest 2002:122:812-20.

24. Wuthrich B, Schindler C, Medici TC, et al. IgE levels, atopy markers and hay fever in relation to age, sex and smoking status in a normal adult Swiss population. SAPALDIA (Swiss Study on Air Pollution and Lung Diseases in Adults) Team. Int Arch Allergy Immunol 1996;111:396-402.

25. Burney PG, Luczynska C, Chinn S, et al. The European Community Respiratory Health Survey. Eur Respir J 1994;7:954-60.

26. Schneider S, Roessli D, Excoffier L. Arlequin ver 2000: A software for population genetics data analysis. Switzerland: Genetics \& Biometry Laboratory, University of Geneva, 2000

27. Fleiss JL. Analysis of data from multiclinic trials. Control Clin Trials 1986;7:267-75

28. Kelada SN, Kardia SL, Walker AH, et al. The glutathione S-transferase-mu and -theta genotypes in the etiology of prostate cancer: genotype-environment interactions with smoking. Cancer Epidemiol Biomarkers Prev 2000;9:1329-34.

29. James A, Carroll N. Airway smooth muscle in health and disease; methods of measurement and relation to function. Eur Respir J 2000;15:782-9.

30. Dulin NO, Fernandes DJ, Dowell M, et al. What evidence implicates airway smooth muscle in the cause of BHR? Clin Rev Allergy Immunol 2003;24:73-84.

31. Shore SA, Fredberg JJ. Obesity, smooth muscle, and airway hyperresponsiveness. J Allergy Clin Immunol 2005:115:925-7.

32. Boulet LP, Laviolette $\mathrm{M}$, Turcotte $\mathrm{H}$, et al. Bronchial subepithelial fibrosis correlates with airway responsiveness to methacholine. Chest 1997;112:45-52.

33. Chetta A, Foresi A, Del Donno $\mathbf{M}$, et al. Airways remodeling is a distinctive feature of asthma and is related to severity of disease. Chest 1997;111:852-7.

34. Prezant DJ, Weiden M, Banauch Gl, et al. Cough and bronchial responsiveness in firefighters at the World Trade Center site. N Engl J Med 2002;347:806-15.

35. Gilmour MI, Jaakkola MS, London SJ, et al. How exposure to environmental tobacco smoke, outdoor air pollutants, and increased pollen burdens influences the incidence of asthma. Environ Health Perspect 2006;114:627-33.

36. Henriksen AH, Sue-Chu M, Holmen TL, et al. Exhaled and nasal NO levels in allergic rhinitis: relation to sensitization, pollen season and bronchial hyperresponsiveness. Eur Respir J 1999;13:301-6.

37. Kohlhaufl M, Brand P, Scheuch G, et al. Increased fine particle deposition in women with asymptomatic nonspecific airway hyperresponsiveness. Am J Respir Crit Care Med 1999;159:902-6.
38. Lau S, Illi S, Platts-Mills TA, et al. Longitudinal study on the relationship between cat allergen and endotoxin exposure, sensitization, cat-specific lgG and development of asthma in childhood: report of the German Multicentre Allergy Study (MAS 90). Allergy 2005:60:766-73

39. Sterk PJ, Fabbri LM, Quanjer PH, et al. Airway responsiveness. Standardized challenge testing with pharmacological, physical and sensitizing stimuli in adults. Report Working Party Standardization of Lung Function Tests, European Community for Steel and Coal. Official Statement of the European Respiratory Society. Eur Respir J Supp/ 1993:16:53-83.

40. Gerbase MW, Schindler C, Zellweger JP, et al. Respiratory effects of environmental tobacco exposure are enhanced by bronchial hyperreactivity. Am J Respir Crit Care Med 2006;174:1125-31

41. Hayes JD, Pulford DJ. The glutathione S-transferase supergene family: regulation of GST and the contribution of the isoenzymes to cancer chemoprotection and drug resistance. Crit Rev Biochem Mol Biol 1995;30:445-600.

42. Adler V, Yin Z, Fuchs SY, et al. Regulation of JNK signaling by GSTp. Embo J 1999;18:1321-34

43. Ruscoe JE, Rosario LA, Wang T, et al. Pharmacologic or genetic manipulation of glutathione S-transferase P1-1 (GSTpi) influences cell proliferation pathways. J Pharmacol Exp Ther 2001;298:339-45.

44. Elsby R, Kitteringham NR, Goldring CE, et al. Increased constitutive c-Jun N-terminal kinase signaling in mice lacking glutathione S-transferase Pi. J Biol Chem 2003;278:22243-9

45. Henderson CJ, Smith AG, Ure J, et al. Increased skin tumorigenesis in mice lacking pi class glutathione S-transferases. Proc Natl Acad Sci USA 1998;95:5275-80.

46. Postma DS, Boezen HM. Rationale for the Dutch hypothesis. Allergy and airway hyperresponsiveness as genetic factors and their interaction with environment in the development of asthma and COPD. Chest 2004;126(2 Suppl):96-104S; discussion 159-61S

47. Nowak D, Jorres R, Schmidt A, et al. Effect of 3 hours' passive smoke exposure in the evening on airway tone and responsiveness until next morning. Int Arch Occup Environ Health 1997;69:125-33.

48. Nowak D, Jorres R, Martinez-Muller L, et al. Effect of 3 hours of passive smoke exposure in the evening on inflammatory markers in bronchoalveolar and nasal lavage fluid in subjects with mild asthma. Int Arch Occup Environ Health 1997;70:85-93.

49. Feleszko W, Zawadzka-Krajewska A, Matysiak K, et al. Parental tobacco smoking is associated with augmented IL-13 secretion in children with allergic asthma. J Allergy Clin Immunol 2006;117:97-102.

50. Cheng YK, Tsai MH, Lin CD, et al. Oxidative stress in nonallergic nasal polyps associated with bronchial hyperresponsiveness. Allergy 2006;61:1290-8.

51. Aynacioglu AS, Nacak M, Filiz A, et al. Protective role of glutathione S-transferase P1 (GSTP1) Val105Val genotype in patients with bronchial asthma. Br J Clin Pharmacol 2004:57:213-7.

52. Lee $\mathbf{Y L}$, Lin $\mathrm{YC}$, Lee $\mathrm{YC}$, et al. Glutathione S-transferase $\mathrm{P1}$ gene polymorphism and air pollution as interactive risk factors for childhood asthma. Clin Exp Allergy 2004;34:1707-13

53. Lee $\mathbf{Y L}$, Hsiue TR, Lee $\mathrm{YC}$, et al. The association between glutathione s-transferase P1, M1 polymorphisms and asthma in Taiwanese schoolchildren. Chest 2005; 128:1156-62

54. Carroll WD, Lenney W, Jones PW, et al. Effects of glutathione S-transferase M1, T1 and P1 on lung function in asthmatic families. Clin Exp Allergy 2005;35:1155-61.

55. Ivaschenko TE, Sideleva OG, Baranov VS. Glutathione- S-transferase micro and theta gene polymorphisms as new risk factors of atopic bronchial asthma. $\mathrm{J} \mathrm{Mol} \mathrm{Med}$ 2002;80:39-43.

56. Tamer L, Calikoglu M, Ates NA, et al. Glutathione-S-transferase gene polymorphisms (GSTT1, GSTM1, GSTP1) as increased risk factors for asthma. Respirology 2004;9:493-8.

57. Kabesch $\mathbf{M}$, Hoefler $\mathbf{C}$, Carr D, et al. Glutathione $\mathbf{S}$ transferase deficiency and passive smoking increase childhood asthma. Thorax 2004;59:569-73.

58. Romieu I, Sienra-Monge JJ, Ramirez-Aguilar M, et al. Genetic polymorphism of GSTM1 and antioxidant supplementation influence lung function in relation to ozone exposure in asthmatic children in Mexico City. Thorax 2004;59:8-10.

59. Pekkanen J, Pearce N. Defining asthma in epidemiological studies. Eur Respir J 1999;14:951-7.

60. Toren K, Brisman J, Jarvholm B. Asthma and asthma-like symptoms in adults assessed by questionnaires. A literature review. Chest 1993;104:600-8.

61. Britton J, Pavord I, Richards K, et al. Factors influencing the occurrence of airway hyperreactivity in the general population: the importance of atopy and airway calibre. Eur Respir J 1994;7:881-7. 